\title{
TEC variations during low solar activity period (2005-2007) near the Equatorial Ionospheric Anomaly Crest region in India
}

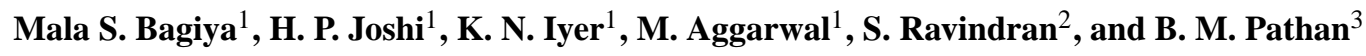 \\ ${ }^{1}$ Department of Physics, Saurashtra University, Rajkot-360005, India \\ ${ }^{2}$ Space Physics Laboratory, Vikram Sarabhai Space Centre, Thiruvanathapuram-695022, India \\ ${ }^{3}$ Indian Institute of Geomagnetism, Navi Mumbai-410218, India
}

Received: 12 July 2008 - Revised: 12 November 2008 - Accepted: 26 November 2008 - Published: 2 March 2009

\begin{abstract}
The dual frequency signals from the GPS satellites recorded at Rajkot $\left(22.29^{\circ} \mathrm{N}, 70.74^{\circ} \mathrm{E}\right.$, Geographic, $14.03^{\circ} \mathrm{N}$ Geomagnetic) near the Equatorial ionization anomaly crest in India have been analyzed to study the ionospheric variations in terms of Total Electron Content (TEC) for the low solar activity period from April 2005 to December 2007. In this study, we describe the diurnal and seasonal variations of TEC, solar activity dependence of TEC and effects of a space weather related event, a geomagnetic storm on TEC. The diurnal variation of TEC shows pre-dawn minimum for a short period of time, followed by a steep early morning increase and then reaches maximum value between 14:00 LT and 16:00 LT. The mean diurnal variations during different seasons are brought out. It is found that TEC at Rajkot is at its maximum during Equinoctial months (March, April, September, October), and minimum during the Winter months (November, December, January, February), with intermediate values during Summer months (May, June, July, August), showing a semi annual variation. TEC values have been decreasing since 2005 , onwards showing positive correlation with solar activity. TEC variations during the geomagnetic storm commencing 24 August 2005 with $D_{s t}=-216$ nT are analysed. TEC shows a positive ionospheric storm effect on the first day of the storm and negative ionospheric storm effect on the next day. The equatorial Electrojet control on the development of the equatorial anomaly is also demonstrated.
\end{abstract}

Keywords. Ionosphere (Equatorial ionosphere; Ionospheric disturbances; Wave propagation)

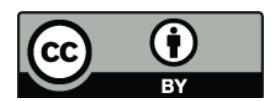

Correspondence to: Mala S. Bagiya (bagiyamala@yahoo.co.in)

\section{Introduction}

The ionospheric effect on satellite communication, satellite tracking and navigational control application are directly proportional to the Total Electron Content, (TEC). Now it is well accepted that a GPS-based navigation system provides accurate, continuous, all-weather three-dimensional location of a user and in recent years the dependence on this navigation system has increased drastically. When the GPS signals propagate through the ionosphere, the carrier experiences a phase advance and the code experiences a group delay due to the total number of free electrons along the path of the signals from the satellite to the receiver. Therefore, the carrier phase pseudoranges are measured too short and the code pseudoranges are measured too long compared to the geometric range between the satellite and the receiver. This results in the degradation of the positional accuracy provided by the GPS receiver (Hofmann-Wellenhof et al., 1992). The effect on the range may vary from the furthest distance of more than hundreds of meters (at mid day, during the period of maximum sunspot activity, with the satellite near the horizon of the observer) to the closest distance of less than a few meters (at night, during the period of minimum solar activity, with the satellite at the zenith). Among the different sources of GPS positional errors, ionospheric delay, which is proportional to the TEC, is the highest contributor. Therefore, in order to get better positional accuracy, it is necessary to have a precise knowledge of the accurate value and the variations of the TEC at different geographical locations and under different geophysical conditions.

TEC variations with local time, season, and solar activity has been studied extensively over the past few decades (Rastogi et al., 1971; da Rosa et al., 1973; Van Velthoven, 1990; Feitcher and Leitinger, 1997; Warnant et al., 2000; Gupta and Singh, 2000; Wu et al., 2008). In the past three decades, several individual measurements of TEC at various locations

Published by Copernicus Publications on behalf of the European Geosciences Union. 
in India have been made using the available low earth orbiting satellites as well as geostationary satellites (Rastogi and Sharma, 1971; DasGupta and Basu, 1973; Rastogi et al., 1975; Rama Rao et al., 1977; Davies at el., 1979). All these studies have shown the characteristic features of the Total Electron Content (TEC) for the Indian region. With the advent of GPS satellites, GAGAN (GPS Aided GEO Augmented Navigation) network of stations monitoring TEC and scintillations in the Indian subcontinent have been established. Using this data and other individual GPS TEC measurements, ionospheric TEC variations have been investigated at a few Indian stations: for example at Waltair (Rama Rao et al., 2005), in the equatorial region and at Udaipur, near the anomaly crest region (Pandey and Dashora, 2006).

Equatorial Ionosphere exhibits large spatial gradients in electron density due to the well-known equatorial ionization anomaly (EIA) with a trough at the equator and a crest at $\sim 15^{\circ}$ north and south geomagnetic latitudes. Rastogi and Klobuchar (1990), using ATS-6 TEC measurements from India, have shown a large day to day variability in the location of the anomaly crest in the Indian sector and its dependence on the equatorial Electrojet and counter Electrojet. Sethia et al. (1980) and Balan and Iyer (1983) have shown that the Electrojet has a pronounced influence on the development of EIA in TEC, based on the sparse data of previous satellites of opportunity.

The present paper describes the TEC behavior using GPS dual frequency measurements at Rajkot, situated near the anomaly crest in India, during the low sunspot activity period 2005 to 2007. Also, some limited data set from the latitudinally distributed chain of GPS receivers, installed as a part of GAGAN program, around the same longitude, which is ideal for the study of EIA, is used to study the control of the Equatorial Electrojet on the EIA.

\section{Ionospheric TEC measurements using the dual fre- quency GPS signals}

The Slant Total Electron Content (STEC) is the measure of the total number of free electrons in a column of the unit cross section along the path of the electromagnetic wave between the satellite and the receiver. The total number of free electrons is proportional to the ionospheric differential delay between L1 (1575.42 MHz) and L2 (1227.60 MHz) signals.

$$
\text { STEC }=\int_{\text {receiver }}^{\text {satellite }} N d s
$$

where $N$ is the electron density; 1 TEC Unit $=10^{16}$ electrons $/ \mathrm{m}^{2}$.
In practice, STEC is obtained from the dual frequency code measurements, given by

$\mathrm{STEC}=\frac{1}{40.3} \times\left(\frac{1}{L_{1}^{2}}-\frac{1}{L_{2}^{2}}\right)^{-1} \times\left(P_{1}-P_{2}\right)+\mathrm{TEC}_{\mathrm{CAL}}$

$P_{1}=$ Pseudo range at $L_{1} ; P_{2}=$ Pseudo range at $L_{2}$.

For our purpose, we use STEC measured by the receiver at every $30 \mathrm{~s}$. The measured STEC is corrected for the receiver differential delay $\mathrm{TEC}_{\mathrm{CAL}}$.

In the above Eq. (1), $\mathrm{TEC}_{\mathrm{cal}}$ represents the bias error correction and is different for different satellite-receiver pairs. In the present study, the receiver part of the above bias is corrected by taking the value of 0.793 TECU supplied by the manufacturer by calibrating the receiver against Wide Area augmentation system (WAAS). As we are mainly concerned with variations of TEC, the above approach is satisfactory. This procedure gives the corrected slant TEC. As slant TEC is dependent on the ray path geometry through the ionosphere, it is desirable to calculate an equivalent vertical value of TEC which is independent of the elevation of the ray path. The Vertical TEC is obtained by taking the projection from the slant to vertical using the thin shell model assuming a height of $350 \mathrm{~km}$, following the technique given by (Klobuchar, 1986):

$$
\begin{aligned}
& \text { Vertical TEC }(\text { VTEC })= \\
& \quad \text { STEC } \times \operatorname{Cos}\left[\operatorname{arc} \sin \left(R_{e} \cos \theta / R_{e}+h_{\max }\right)\right]
\end{aligned}
$$

where $R_{e}=6378 \mathrm{~km}, h_{\max }=350 \mathrm{~km}, \theta=$ elevation angle at the ground station.

Rama Rao et al. (2006) observed that the IPP (Ionospheric Pierce Point) altitude of $350 \mathrm{~km}$ is valid for the Indian region for satellite elevation angle greater than $50^{\circ}$. For the satellite elevation angle lower than the $50^{\circ}$, they further showed that the calculated VTEC is critically dependent on the IPP latitude.

A program is developed to perform the data sorting and analysis for the long-term study. To obtain the vertical TEC at Rajkot, we are restricted to a longitude grid of $\pm 2^{\circ}$ and latitude grid of $\pm 2^{\circ}$ from the observing station, in addition to the $50^{\circ}$ elevation cut-off.

\section{Observations, results and discussion}

In order to study the TEC variations with local time, season, solar activity and geomagnetic condition, we have used a data base from April 2005 to December 2007 recorded at Rajkot (with an exception of some months when observations were disrupted by instrument problems). To study the electorjet effect on low latitude TEC, we have used the magnetic data $[\Delta H$ (Tirunelveli) $-\Delta H$ (Alibag) $]$ provided by the Indian Institute of Geomagnetism, Mumbai, India. During the period of observation, the solar $10.7 \mathrm{~cm}$ flux decreased from $82.6 \mathrm{sfu}$ to $67.3 \mathrm{sfu}$ (1 Solar Flux Unit ( $\mathrm{sfu})=10^{-22}$ watt $\mathrm{m}^{-2} \mathrm{~Hz}^{-1}$ ). 


\subsection{Diurnal variation of TEC}

The diurnal pattern of TEC exhibits a steady increase from about sunrise to an afternoon maximum and then falls to attain a minimum just before sunrise. The diurnal characteristics of TEC have seasonal, solar activity, geomagnetic activity and latitudinal dependence. Figure 1 shows the diurnal pattern for a typical quiet day of 17 April $2005\left(A_{p}=4\right)$ derived from TEC value for every minute. It is derived for a $\pm 2^{\circ}$ latitude and $\pm 2^{\circ}$ longitude bin from the Rajkot for all the visible satellites. The variations can be divided into three different sections, namely: the build up region, the day time plateau and the decay region. The diurnal variation in TEC at Rajkot exhibits many characteristics typical to low latitude ionosphere such as a TEC minimum at pre-dawn and gradual increase with the time of day attaining a maximum in the afternoon and a gradual decrease after sunset. The daily peak occurs around 14:00 IST (IST=UT+5.5 h). In low latitude regions, the highest daytime peak TEC values depend greatly on the strength of the equatorial ionization anomaly. Figure 2 shows the mass plots of TEC diurnal variations for the months of 2005, 2006 and 2007. These curves show appreciable day to day variability. The day to day variability of TEC is contributed by the various parameters like EUV flux, geomagnetic activity (Dabas et al., 1984), Electrojet strength and local atmospheric conditions in the thermosphere (Rama Rao et al., 1980) etc.

\subsection{Seasonal variation of TEC}

The mean diurnal TEC variations during different seasons recorded at Rajkot for the years of 2005-2007, are shown in Fig. 3. The TEC values are high in equinoctial months followed by more or less similar values in summer and winter. Thermospheic neutral composition has a direct control on the seasonal variation of TEC. During the daytime, the equator is hotter than the pole therefore meridional wind flows towards the pole from the equator. This flow of meridional wind changes the neutral composition and $\mathrm{O} / \mathrm{N}_{2}$ decreases at equatorial and low latitude stations. In equinox, this decrease will be maximum. At $350 \mathrm{~km}$ altitude (F2 layer), $\mathrm{N}_{2}$ dissociation is the major process which removes ambient electrons. Hence, the decrease in $\mathrm{O} / \mathrm{N}_{2}$ ratio will result in higher electron density and therefore in equinox TEC will be highest.

There is a sharp daily maximum during 2005-2006 compared to 2006-2007 for all seasons. During the low solar activity period, the seasonal variability of daily peak TEC is comparatively low which agrees with the results shown by Modi and Iyer (1989).

Figure 4 shows the month to month variation of monthly mean diurnal peak TEC values.

The diurnal peak TEC shows semiannual variation with a peak during the equinox period and a trough during the solstice period. As the solar flux value decreases from 2005 onwards, the measured TEC also exhibits lower magnitude

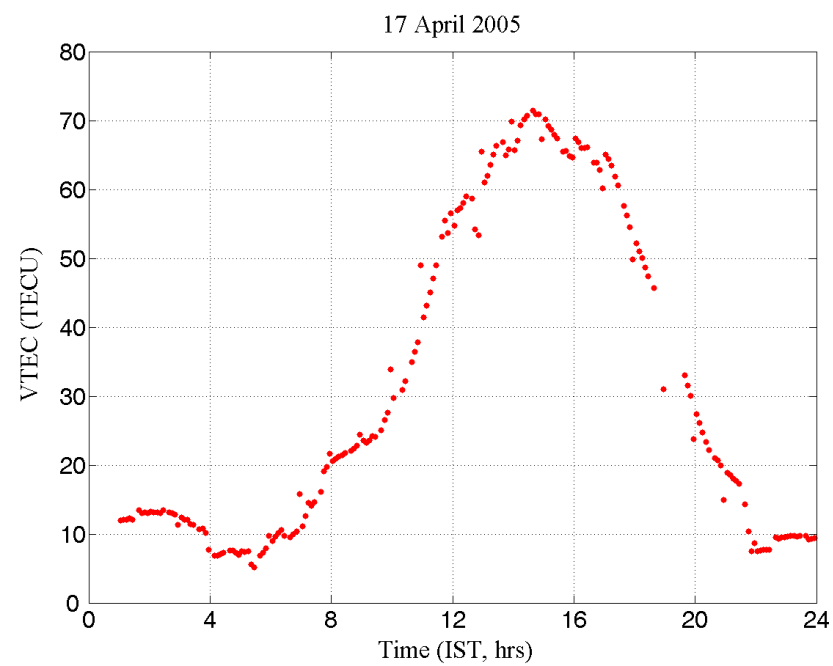

Fig. 1. Diurnal variation of TEC observed for a $\pm 2^{\circ}$ latitude and $\pm 2^{\circ}$ longitude bin from the observing station Rajkot $\left(22.29^{\circ} \mathrm{N}\right.$, $70.74^{\circ} \mathrm{E}, 14.29^{\circ} \mathrm{N}$ Geomagnetic).

for the year 2006-2007 in comparison to 2005-2006. The spring equinox shows larger value than the autumn equinox.

\subsection{Solar activity dependence of TEC}

The Sun emits a wide spectrum of radiation along with high energy particles. Along with the sunspot number, the flux of the Sun's radio emission at a wavelength of $10.7 \mathrm{~cm}$ $(2.8 \mathrm{GHz})$ is a useful indicator of solar activity relevant for ionospheric effects. Rama Rao et al. (1985) reported the direct control of solar activity on the ionization level, with higher values during a high solar activity period and low value during a low solar activity period. Although the range of solar flux variation during the present period of observation is very limited, Fig. 5 shows high positive correlation (Correlation Coefficient $R=0.99$ ) between daytime peak TEC and the solar F10.7 flux. During the period of a low sunspot number, the TEC builds up quite slowly, resulting in a low value of day maximum. Warnant et al. (2000) have reported higher values of TEC with increasing solar activity.

\subsection{TEC variations during a space weather event}

The effect of a geomagnetic storm on the ionospheric electron content has been studied by many workers (Jakowaski et al., 1999; Sastri et al., 2002; Maruyama et al., 2004; Mannucci et al., 2005). Pandey and Dashora (2005) reported both positive and negative storm effects using GPS TEC measurements at Udaipur $\left(26.4^{\circ} \mathrm{N} 73.7^{\circ} \mathrm{E}\right.$, Geographic, $15.6^{\circ} \mathrm{N}$ Geomagnetic), a station near the anomaly crest. The TEC response to the storm depends on the local time of the Storm Sudden Commencement (SSC). In the case of a day time SSC storm, a prompt penetration electric field directed eastward raises low latitude plasma upward due to the $\boldsymbol{E} \times \boldsymbol{B}$ drift 

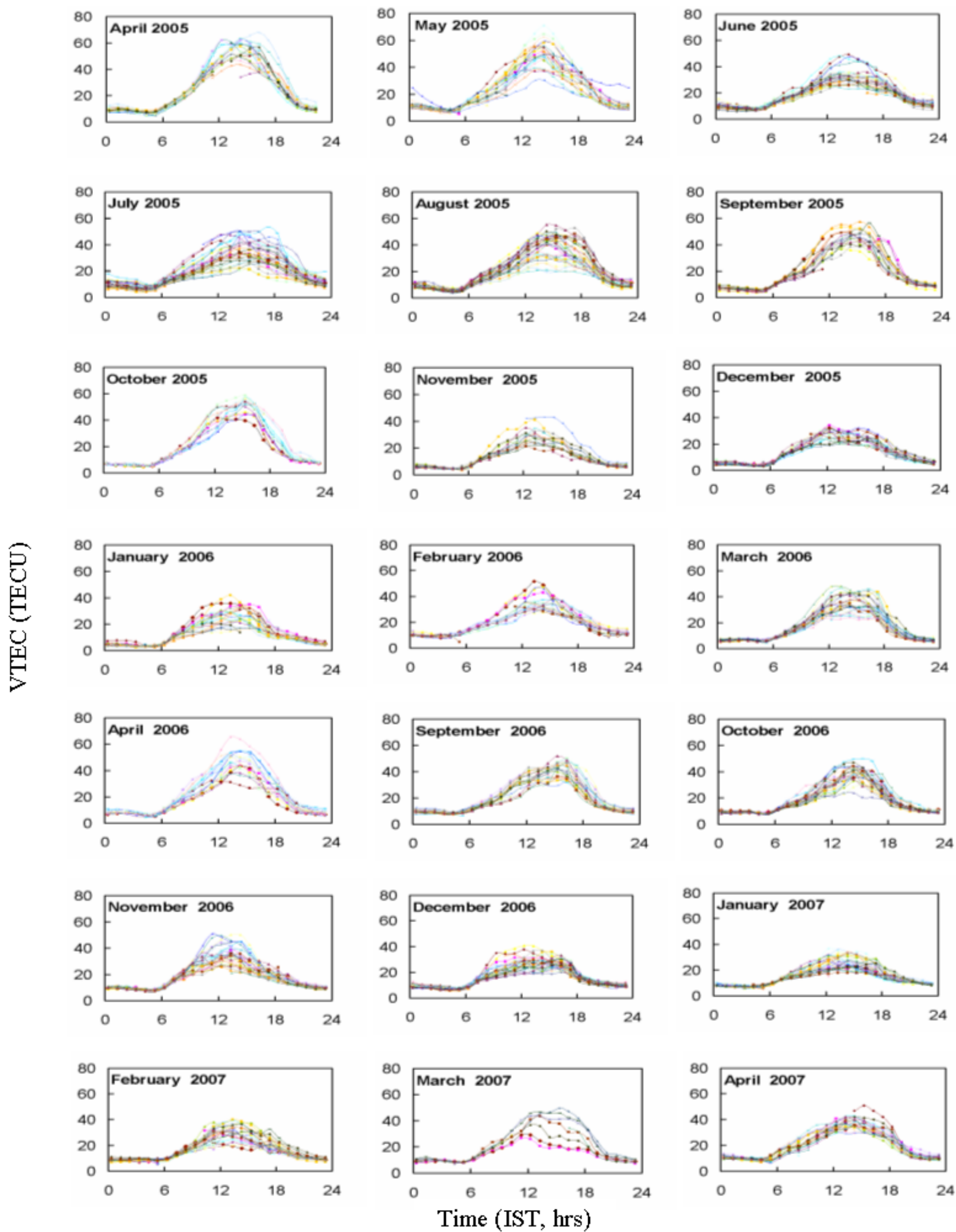

Fig. 2. Mass plot of Diurnal variation of Total Electron Content at Rajkot from April 2005 to April 2007 with the exception of May to August 2006 due to instrument failure. 


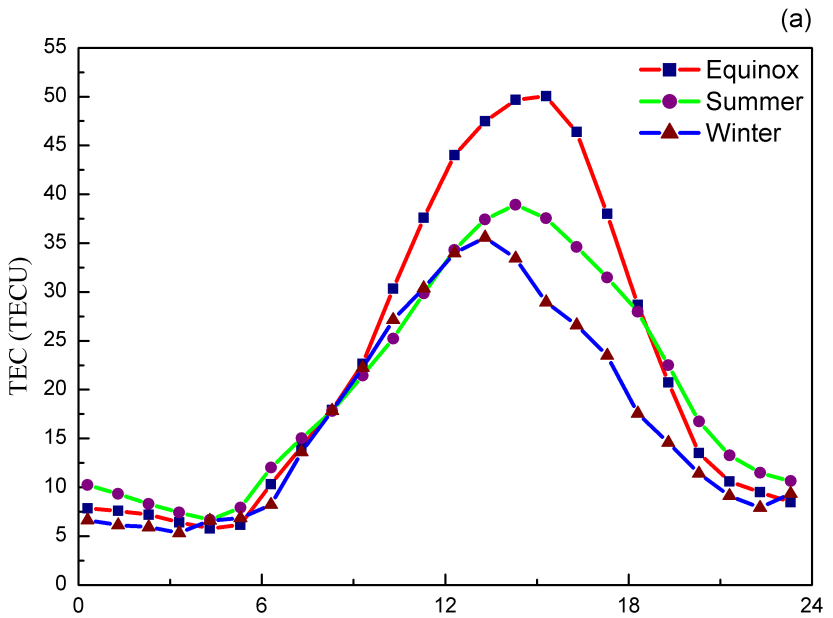

(b)

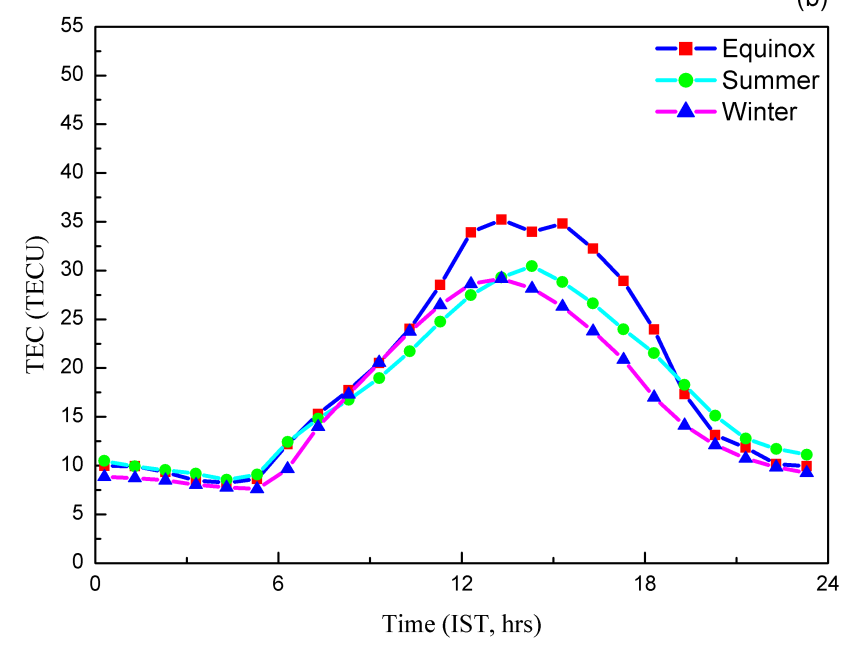

Fig. 3. Seasonal mean Diurnal variation of TEC during (a) 20052006 and (b) 2006-2007 at Rajkot.

where the recombination rate is slow. An increase in the electrodynamic drift will lift more plasma from the equatorial region which diffuses down along the field lines to higher latitudes and results in the increase of the TEC at stations under the anomaly crest region. From the ATS- 6 observation in India, Jain et al. (1978) presented the daytime storm effect on TEC with respect to Equatorial Electrojet.

The effect of a typical geomagnetic storm of 24 August 2005 (SSC at 14:00 IST) on TEC variation at our latitudes, is shown in Fig. 6. Figure 6a shows the variation with Local time (Indian Standard Time, IST) in the $B_{z}$ component of the interplanetary magnetic field, solar wind speed $V_{p}$ and proton density $N_{p}$ during the period 23-27 August 2005. Figure $6 \mathrm{~b}$ shows the IST variations in $D_{s t}, K_{p}$ and TEC during the 23-27 August 2005. The mean TEC variation for the quiet days of the month is shown by the solid line curve in the bottom panel. The equatorial $D_{s t}$, which is the best measure of the storm intensity, has gone down to its minimum of

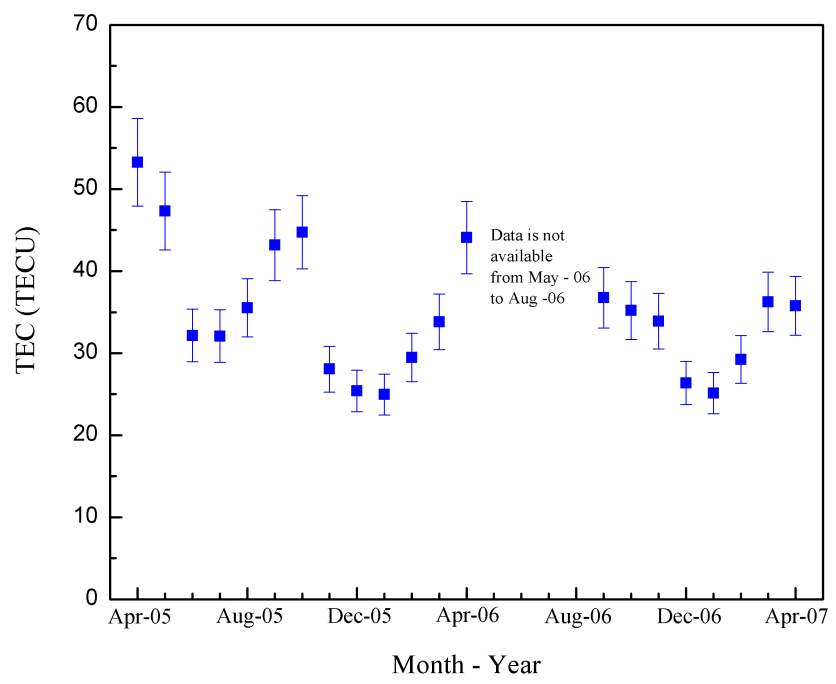

Fig. 4. Month-to-month Variation of TEC, daily mean peak, (20052007) at Rajkot.

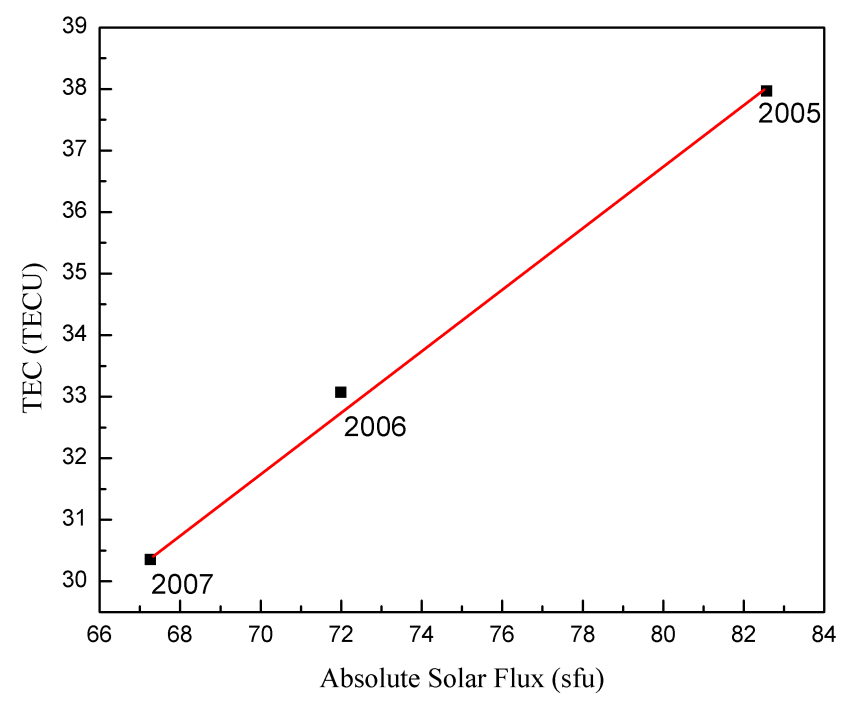

Fig. 5. Solar Cycle dependence of TEC plotted for the Rajkot GPS data.

$-216 \mathrm{nT}$ during the storm period at 19:00 IST on 24 August, after $5 \mathrm{~h}$ of storm commencement and the corresponding, $K_{p}$ value is 9 and $A_{p}$ value is 102 . TEC shows an increment of 20 TECU on the day of 24 August at 18:00 IST, with respect to average quiet days' value. On 25 August, it decreases by 18 TECU with respect to average quiet days' value. As the SSC occurred at sunlit hours, the daytime eastward electric field is probably enhanced due to prompt penetration of interplanetary electric field before the shielding occurs, which is responsible for the TEC increase on the SSC day of $24 \mathrm{Au}-$ gust 2005. $D_{s t}$ decreased at a rate of $26 \mathrm{nT} / \mathrm{h}$ between 15:00 and 16:00 IST after onset at 14:00 IST. Then it fluctuated up and down between 16:00 IST and 18:00 IST. It decreased at 

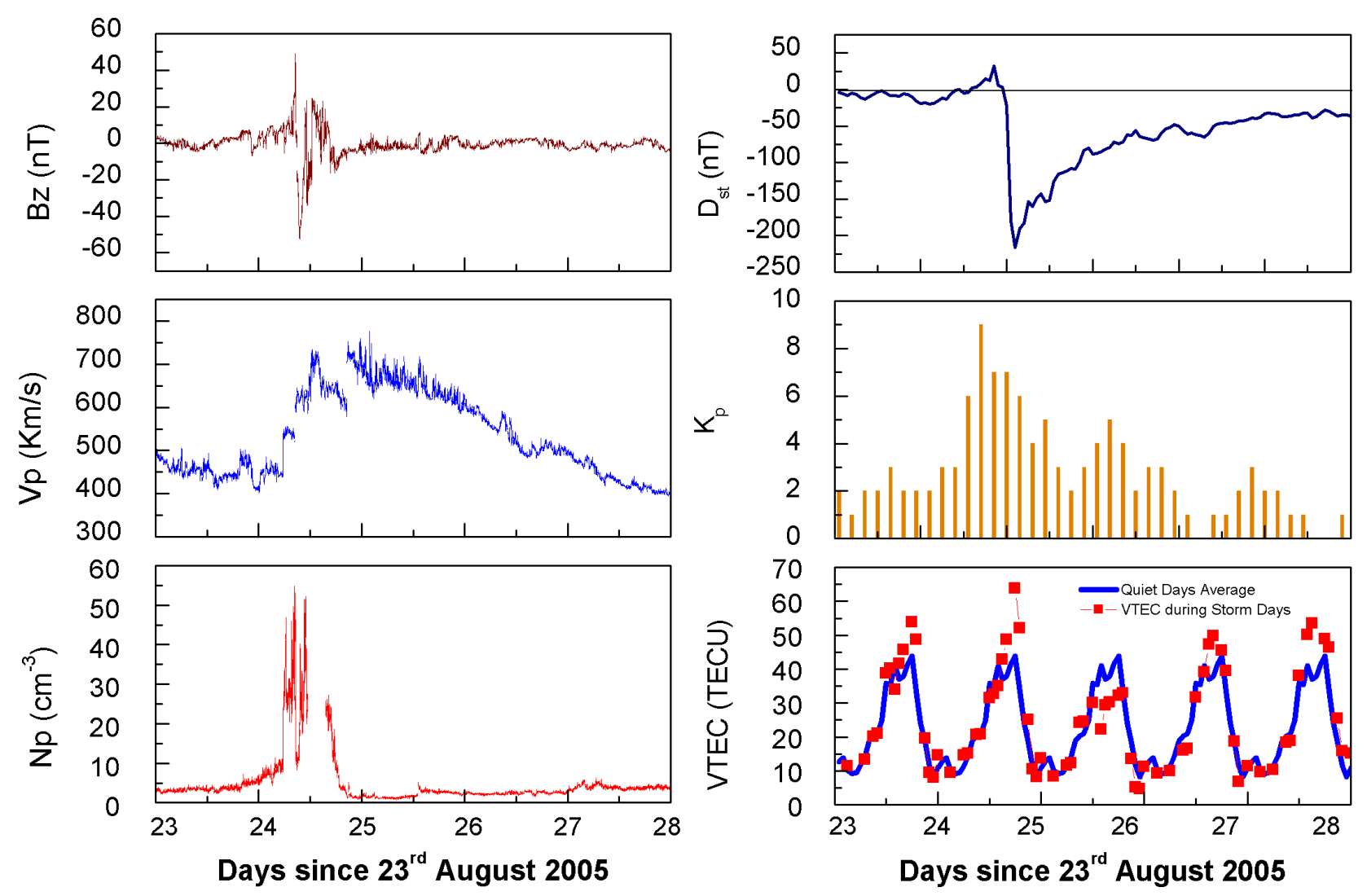

Fig. 6. (a) The variations of interplanetary magnetic field $B_{z}$, solar wind velocity $V_{p}$, and proton density $N_{p}$ during geomagnetic storm event of 23-27 August 2005. (b) The variations of $D_{s t}, K_{p}$ and TEC (red dashed line) during 23-27 August 2005. The quiet days' mean TEC of the month is shown by the solid blue line in the bottom panel (day hours are in IST).

a rate of $158 \mathrm{nT} / \mathrm{h}$ between 18:00 and 19:00 IST. TEC increase is also seen at 18:00 IST on 24 August. This is the direct evidence of a PP electric field over low and equatorial latitudes during the time of maximum rate of decrease of $D_{s t}$. IEFy maximum value of $29.53 \mathrm{mV} / \mathrm{m}$ at $\sim 16: 31$ IST is inferred at the equatorial ionosphere, from the calculations based on ACE data. It is reasonable to expect an ionospheric response time of $\sim 1.5 \mathrm{~h}$ (from 16:31 to $18: 00$ IST) from the time of impingement of electric field and ionospheric TEC enhancement near the anomaly crest, also observed by Tsurutani et al. (2008) for the 30 October 2003 storm.

The enhanced electric field results in the stronger plasma fountain which transfers more plasma to anomaly crest regions. A similar increase of TEC was reported for the super storm of 20 November 2003 in the Brazilian low latitude sector by Becker-Guedes et al. (2007). The subsequent day decrease (negative storm phase) may be due to thermospheric winds and neutral composition changes produced by the storm time Joule heating. During the storm onset $\left[\mathrm{O} / \mathrm{N}_{2}\right]$ decreases at high latitudes and enhanced at lower latitudes (Meier et al., 2005). Figure 7 shows the TIMED/GUVI images which shows $\left[\mathrm{O} / \mathrm{N}_{2}\right]$ enhancement on the storm day of
24 August 2005. On 25 August 2005, there is depletion in the $\left[\mathrm{O} / \mathrm{N}_{2}\right]$ ratio as observed by GUVI. Electron loss at F2 peak depends upon the recombination/attachment with $\mathrm{N}_{2}$; as $\mathrm{N}_{2}$ density decreases, electron density will increase giving positive storm and vice versa.

The pre-storm enhancement on 23 August 2005 may be due to the enhanced zonal electric field or vertical drift. This may be due to the aftermath of a previous geomagnetic activity or direct mapping of a magnetospheric (Interplanetary) electric field to the equatorial electric field or the effect of a planetary wave activity as discussed by Liu et al. (2008). It needs further investigation to ascertain the exact cause.

The penetration of a magnetospheric electric field equatorward of the mid latitude shielding region occurs during the time of rapid changes in $D_{s t}$ with time (as in this case between SSC and $D_{s t} \mathrm{~min}$ ). PP effect occurs in the specific longitude sector for which the early evening period corresponds to the time of rapid $D_{s t}$ change and minimum $D_{s t}$. Such penetration effects were reported by Batista et al. (1991) for the great magnetic storm of 13 March 1989, by Basu et al. (2001) for the 22 September and 22 October 1999 storms and for the superstorms of October-November 2003 by Sahai 
GUVI O/N 2 Ratio August 24, 2005

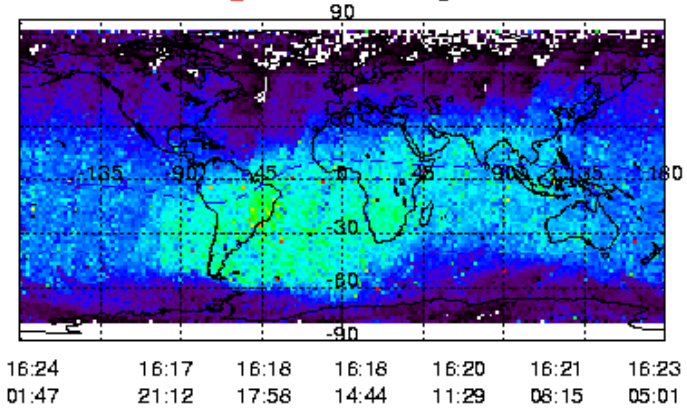

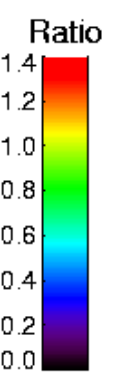

GUVI $\mathrm{O} / \mathrm{N}_{2}$ Ratio August 25, 2005

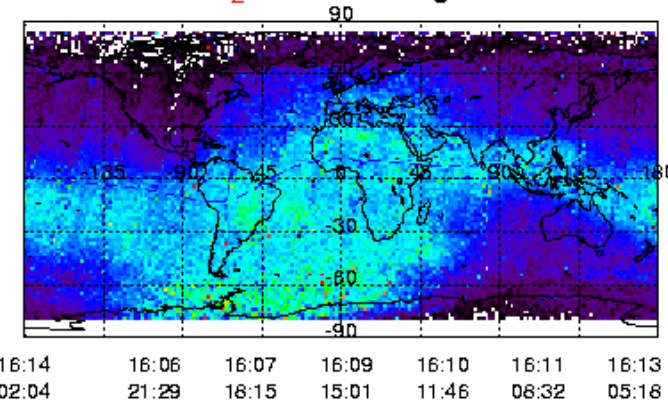

Ratio

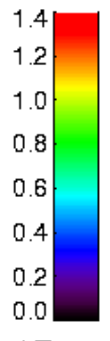

LT

Fig. 7. TIMED/GUVI images showing thermospheric $\mathrm{O} / \mathrm{N}_{2}$ ratio during geomagnetic events of 24 and 25 August 2005 .

et al. (2005) and Becker Guedes et al. (2007) all for the equatorial and low latitude region. The PP electric field effects are generally sharp and short lived $(<1 \mathrm{~h})$ (Fejer and Emmert, 2003) similar to that observed by the TEC increase on 24 August in this case. A more slowly varying (a few to several hours) low latitude disturbance negative effects, during and upto a day or two after the $D_{s t}$ minimum occurs (storm recovery phase), as observed on 25 August in this case are generally due to a disturbance dynamo electric field (Blanc and Richmond, 1980; Spiro et al., 1988) or due to thermospheric composition changes (Greenspan et al., 1991). In the present case, the GUVI maps support the latter mechanism though the role of a disturbance dynamo electric field cannot be ruled out.

\subsection{Equatorial Electrojet control on low latitude TEC}

Equatorial Electrojet (EEJ) is an intense eastward current flowing in the equatorial ionospheric E-region at about a $105 \mathrm{~km}$ altitude. As it is already mentioned in the introduction, EEJ controls the strength and latitudinal extent of equatorial ionization anomaly. In our study, we have tried to study the TEC variation under strong, weak and counter Electrojet conditions for four geomagnetically quiet days. In Fig. 8, we plot the diurnal variation of TEC at Rajkot for the four different cases: (a), 9 April $2005\left(A_{p}=3\right)$, strong Electrojet day with EEJ peak value of 81, TEC attains the value of $\sim 70 \mathrm{TECU}$ on this day and the daily peak occurred at $\sim$ 13:00 IST; (b) 3 July $2005\left(A_{p}=7\right)$ a day of weak Electrojet, TEC value goes down to $\sim 41 \mathrm{TECU}$, and the TEC peak occurred at $\sim$ 15:00 IST. (c) 5 December $2005\left(A_{p}=3\right.$ ), an afternoon counter Electrojet day, TEC shows two maxima one at around $\sim 12: 00$ IST and second at $\sim 16: 00$ IST. TEC maximum is $\sim 42$ TECU. In (d) we have shown the effect of morning counter Electrojet. It is clearly visible that on the morning counter Electrojet day, daily TEC peak has not occurred at all and a broad and flat TEC variation is seen. This may be due to the inhibition of EIA on this day because of the downward $\boldsymbol{E} \times \boldsymbol{B}$ drift in the fore noon hours.
On strong EEJ days, the EIA also intensifies transferring more plasma to the crest region and on the counter EEJ day, the anomaly is suppressed and TEC shows low values near the crest region. Thus our results suggest that EEJ fully controls the EIA, and hence the distribution of F-layer plasma in the low latitude ionosphere. These results also agree with the results shown by Rama Rao et al. (1983) and Rastogi and Klobuchar (1990).

In order to see the latitudinal distribution of TEC and its relation with EEJ, we have derived contour plots of TEC with respect to local time and magnetic latitude for three quiet days, but with different Electrojet conditions, using GAGAN GPS data of five stations: Trivandrum $\left(0.5^{\circ} \mathrm{N} \mathrm{Ge}-\right.$ omagnetic), Bangalore (4.58 $\mathrm{N}$ Geomagnetic), Hyderabad (9.2 $2^{\circ} \mathrm{N}$ Geomagnetic), Bhopal (15.2 $2^{\circ} \mathrm{N}$ Geomagnetic) and Delhi (20.38 ${ }^{\circ} \mathrm{N}$ Geomagnetic). All these stations are around the common longitude belt of $77-78^{\circ} \dot{E}$. In Fig. 9a, the contour TEC plot for the day of 25 December 2005 suggests that, due to counter Electrojet anomaly peak occurred with $\sim 35$ TECU only. The peak was delayed upto $\sim 16: 00$ IST. This is also the case with the morning counter Electrojet. On such days anomaly is totally inhibited with a spatial extent of $\sim 6^{\circ}$ north. This supports our above presented result for our low latitude station. Due to inhibition of EIA, plasma will not get transfered to higher latitudes. On 23 October 2005, the EEJ peak strength was 31 . The anomaly peak occurred at $\sim 14: 00$ IST with $\sim 45 \mathrm{TECU}$ and it extended up to $10^{\circ}$ north, Fig. 9b. In Fig. 9c, it is clearly seen that on the day of strong Electrojet, 20 October 2005, anomaly peaks at a comparatively high value of $\sim 55$ TECU and earlier at 14:00 IST. The latitudinal extent is $\sim 14^{\circ}$ north. On the counter Electrojet day the anomaly can not be developed fully, hence peaks, at lower latitude with low magnitude, are observed. Again, the control of Electrojet on EIA and the low latitude TEC distribution is clearly demonstrated. Dabas et al. (1984) reported that the equatorial Electrojet has a pronounced influence on TEC over a large latitudinal belt starting from the equator to $25^{\circ} \mathrm{N}$ dip latitude. Rama Rao et al. (2005) have shown that equatorial Electrojet controls the altitude of the lifted 

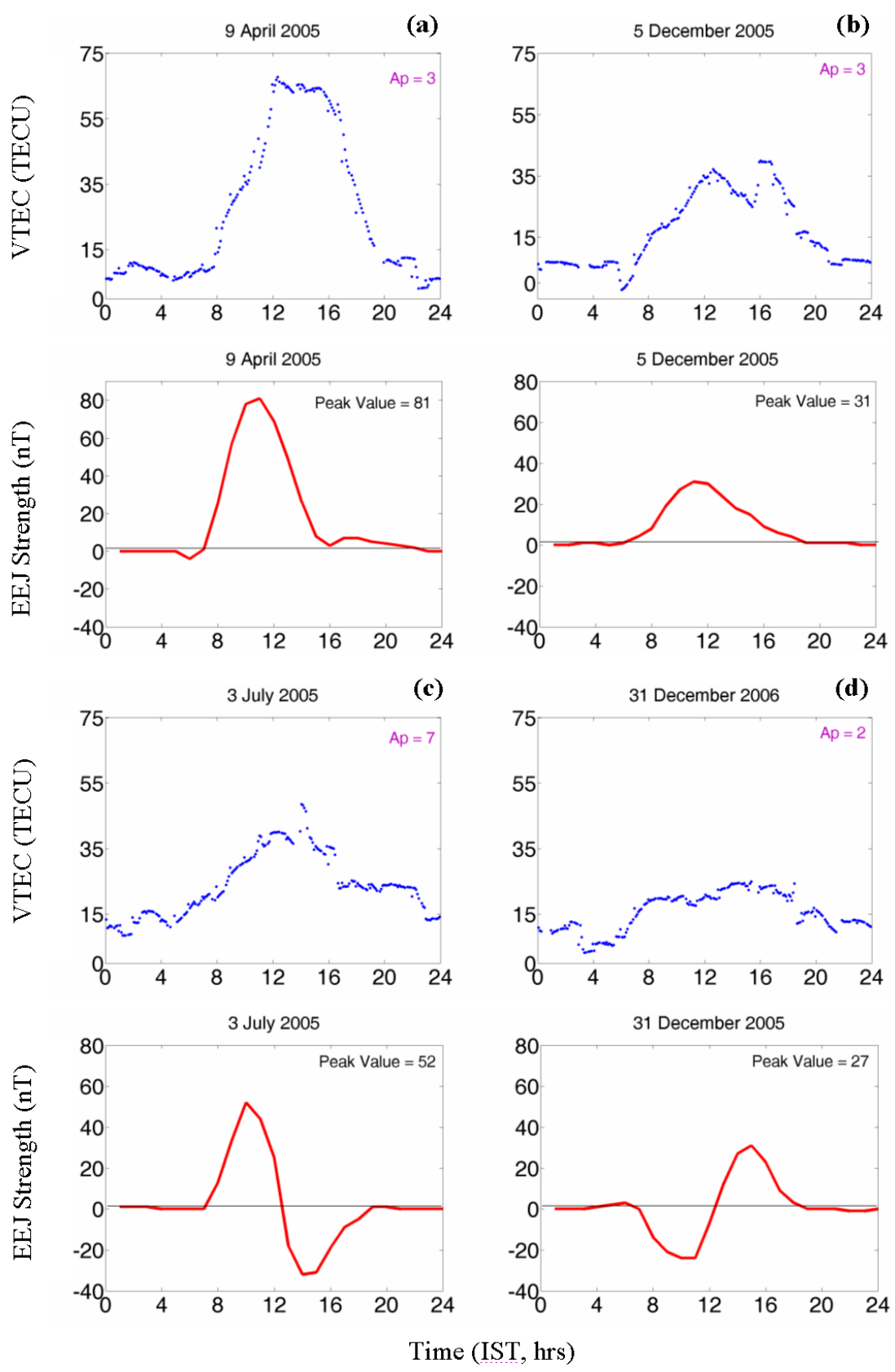

Fig. 8. EEJ control on diurnal variation of TEC on the day of (a) 9 April 2005, (b) 3 July 2005, (c) 5 December 2005, (d) 31 December 2006, representing Strong, Weak, Afternoon Counter Electrojet and Morning Counter Electrojet conditions, respectively.

plasma and the location of the crest of the equatorial ionization anomaly, the higher the Electrojet strength the higher the altitude to which plasma is lifted at the equator and the farther the location is of the crest of the equatorial ionization anomaly. They have shown the spatial variation of TEC and dependence of EIA on EEJ using GPS data of 7 stations of the GAGAN network. Our results agree with this study showing positive dependence of EIA on EEJ.
The statistical correlation between EIA strength and EEJ strength is presented in Fig. 10. It shows that EIA strength increases as the EEJ peak value increases. There is a good linear correlation between EIA strength and EEJ peak value. The scattered points around the regression line may be due to other factors contributing to the day-to-day variability of TEC, although only magnetically quiet days are considered in this analysis. 
25 $5^{\text {th }}$ Dec 2005

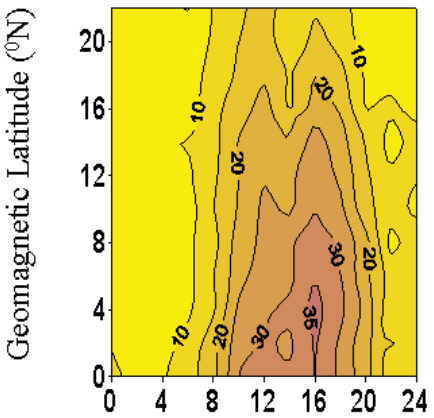

$23^{\text {rd }}$ Oct 2005

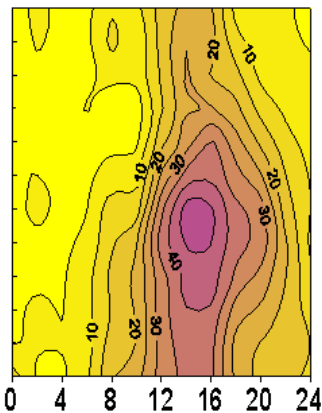

$20^{\text {th }}$ Oct 2005

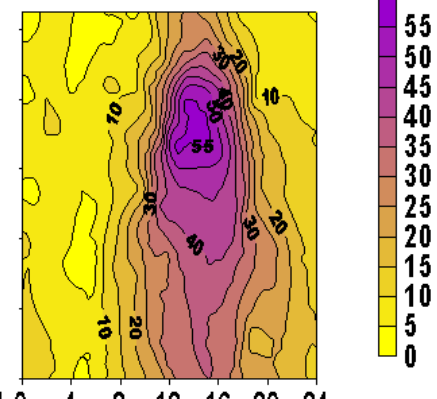

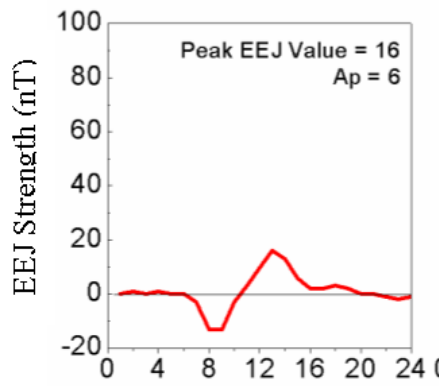
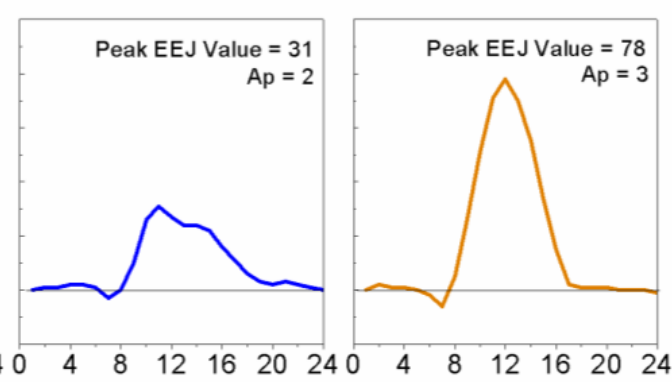

Time (IST, hrs)

Fig. 9. Equatorial Ionization Anomaly development using GAGAN GPS data for different days showing its dependence on EEJ.

\section{Summary}

The present paper describes the TEC variations (diurnal, seasonal, and solar activity dependent and under disturbed geomagnetic conditions) for the low solar activity period (2005-2007) at the low latitude station Rajkot (near anomaly crest; $22.29^{\circ} \mathrm{N}, 70.74^{\circ} \mathrm{E}$, Geographic, $14.29^{\circ} \mathrm{N}$ Geomagnetic). Typically, the diurnal profile of the TEC maximizes at about 14:00 LT, with a minimum in the pre-dawn period. The maximum TEC observed during this span of observations is on the quiet $\left(A_{p}=7\right) 10$ May 2005 with diurnal peak value of $\sim 71 \mathrm{TECU}$. On this day, the solar $10.7 \mathrm{~cm}$ radio flux was $\sim 109.5$. The minimum TEC value observed on the quiet $\left(A_{p}=5\right)$ day of 23 January 2007 with a diurnal peak value of $\sim 19$ TECU. The value of the solar radio flux for the particular day was $69.2 \mathrm{sfu}$. The results presented show a good positive correlation between solar activity and TEC values. During the geomagnetic storm of 24 August 2005, the TEC variation shows typical low latitude characteristics being highest on the storm day and lower on the next consecutive day. The SSC occurred during the daytime, therefore, TEC increments on the storm day can be explained in terms of prompt penetration of the electric field (IEFy $=29.53 \mathrm{mV} / \mathrm{m}$ on 24 August 2005) which raises more plasma to higher altitude through the fountain effect which diffuses along the magnetic field lines up to higher latitudes.

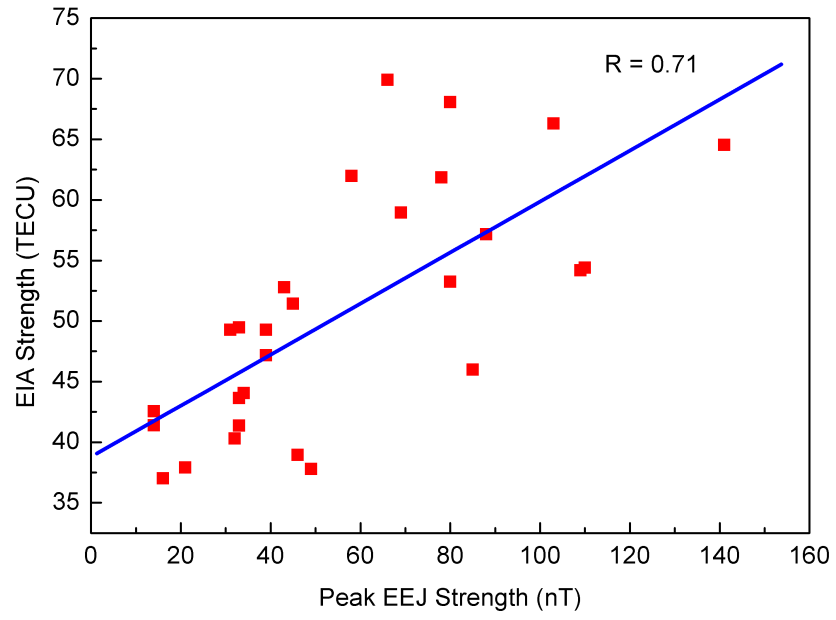

Fig. 10. Statistical correlations between EIA strength and EEJ peak value. $R$ shows the value of Correlation Coefficient.

TEC depletion on 25 August may be due to thermospheric neutral composition changes caused by Joule heating at auroral latitudes as confirmed from the TIMED/GUVI images. The pre-storm enhancement on 23 August 2005 is due to the enhanced zonal electric field or vertical drift (Lui et al., 2008). Our results indicate that low latitude TEC magnitude 
and daily peak time depends on the EEJ conditions. The latitudinal variation of TEC derived from the data of 5 GAGAN GPS stations, further show that the EIA parameters, viz, the anomaly peak value, time and latitudinal extent are greatly controlled by EEJ. EIA is completely inhibited on the day of morning counter Electrojet, resulting in a lower TEC value at Rajkot.

Acknowledgements. We are thankful to World Data Center for Geomagnetism, Kyoto, for providing us the $D_{s t}$ and $K_{p}$ values. We thank ACE SWEPAM and MAG teams as well as ACE science centre for providing us the ACE data. We thank NASA Data Center for providing us TIMED/GUVI images and NOAA Data Center for providing us Solar F10.7 flux values.

One of the authors (KNI) thanks R. Sridharan, Director, SPL, Thiruvanathapuram, for providing facilities under the ADREF scheme of ISRO. This research is sponsored by ISRO under CAWSES.

Topical Editor M. Pinnock thanks two anonymous referees for their help in evaluating this paper.

\section{References}

Balan, N. and Iyer, K. N.: Equatorial anomaly in ionospheric total electron content and its relation to dynamo currents, J. Geophys. Res., 88, 10259-10262, 1983.

Basu, Su., Basu, S., Valladares, C. E., Yeh, H.-C., Su, S.-Y., Mackenzie, E., Sultan, P. J., Aarons, J., Rich, F. J., Doherty, P., Groves, K. M., and Bullet, T. W.: Ionospheric effects of major magnetic storms during the International Space Weather Period of September and October 1999: GPS observations, VHF/UHF scintillations, and in situ density structures at middle and equatorial latitudes, J. Geophys. Res., 106, 30389-30413, 2001.

Batista, I. S., de Paula, E. R., Abdu, M. A., and Trivedi, N. B.: Ionospheric effects of the March 13, 1989 magnetic storm at low and equatorial latitudes, J. Geophys. Res., 96, 13943-13952, 1991.

Becker-Guedes, F., Sahai, Y., Fagundes, P. R., Espinoza, E. S., Pillat, V. G., Lima, W. L. C., Basu, Su., Basu, Sa., Otsuka, Y., Shiokawa, K., MacKenzie, E. M., Pi, X., and Bittencourt, J. A.: The ionospheric response in the Brazilian sector during the super geomagnetic storm on 20 November 2003, Ann. Geophys., 25, 863-873, 2007, http://www.ann-geophys.net/25/863/2007/.

Blanc, M. and Richmond, A. D.: The ionospheric disturbance dynamo, J. Geophys. Res., 85, 1669-1686, 1980.

Dabas, R. S., Bhuyan, P. K., Tyagi, T. R., Bhardwaj, R. K., and Lal, J. B.: Day-to-day changes in ionospheric electron content at low latitudes, Radio Sci., 19, 749-756, 1984.

da Rosa, A. V., Waldman, H., Bendito, J., and Garriott, O. K.: Response of the ionospheric electron content to fluctuations in solar activity, J. Atmos. Terr. Phys., 35, 1429-1442, 1973.

Dasgupta, A. and Basu, A.: Investigation of ionospheric electron content in the equatorial region as obtained by orbiting beacon satellites, Ann. Geophys., 29, 409-419, 1973.

Davies, K., Donnelly, R. F., Grubb, R. N., and Rama Rao, P. V. S.: ATS-6 satellite radio beacon measurements on Ootacamund, India, Radio Sci., 14, 85-95, 1979.

Davies, K.: Recent progress in satellite radio beacon studies with particular emphasis on the ATS-6 Radio beacon experiment, Space Sci. Rev., 25, 357-430, 1980.
Feichter, E. and Leitinger, R.: A 22-year cycle in the F layer ionization of the ionosphere, Ann. Geophys., 15, 1015-1027, 1997, http://www.ann-geophys.net/15/1015/1997/.

Fejer, B. G. and Emmert, J. T.: Low-latitude ionospheric disturbance electric field effects during the recovery phase of the 1921 October 1998 magnetic storm, J. Geophys. Res., 108(A12), 1454, doi:10.1029/2003JA010190, 2003.

Greenspan, M. E., Rasmussen, C. E., Burke, W. J., and Abdu, M. A.: Equatorial density depletions observed at $840 \mathrm{~km}$ during the great magnetic storm of March 1989, J. Geophys. Res., 96, 13931-13942, 1991.

Gupta, J. K. and Singh, L.: Long term ionospheric electron content variations over Delhi, Ann. Geophys., 18, 1635-1644, 2000, http://www.ann-geophys.net/18/1635/2000/.

Hofmann-Wellenhof, B., Lichtenegger, H., and Collins, J.: Global Positioning System, Theory and Practice, 4th edition, SpringerVerlag, Berlin, Heidelberg, New York, 389 pp. 1992.

Jakowaski, N., Schluter, S., and Sardon ,E. : Total Electron Content of ionosphere during the geomagnetic storm of January 1997, J. Atmos. Sol. Terr. Phys., 61, 299-307, 1999.

Klobuchar, J.: Design and characteristics of the GPS ionospheric time-delay algorithm for single frequency users, in: Proceedings of PLANS'86 - Position Location and Navigation Symposium, Las Vegas, Nevada, p. 280-286, 4-7 November 1986.

Liu Libo, Wan Weixing, Zhang Man-Lian, Zhao Biqiang, and Ning Baiqi: Prestorm enhancements in NmF2 and total electron content at low latitudes, J. Geophys. Res., 113, A02311, doi:10.1029/2007JA012832,2008.

Mannucci, A. J., Tsurutani, B. T., Iijima, B. A., Komjathy, A., Saito, A., Gonzalez, W. D., Guarnieri, F. L., Kozyra, J. U., and Skoug, R.: Dayside glonal ionospheric response to the major interplanetary events of October 29-30. 2003 "Halloween Storms", Geophys. Res. Lett., 32, L12S02, doi:10.1029/2004GL021467, 2005.

Maruyama, T., Ma, G., and Nakamura, M.: Signature of TEC storm on 6 November 2001 derived from dense GPS receiver network and ionosonde chain over Japan, J. Geophys. Res., 109, A10302, doi:10.1029/2004JA019451, 2004.

Meier, R. R., Crowley, G., Strickland, D. J., Christensen, A. B., Paxton, L. J., Morrison, D., and Hackeert, C. L.: First look at the 20 November superstorm with TIMED/GUVI: Comparisons with a thermospheric global circulation model, J. Geophys. Res., 110, A09S41, doi:10.1029/2004JA010990, 2005.

Modi, R. P. and Iyer, K. N.: IEC and slab thickness near the peak, Indian J. Radio Space Phys., 18, 23-26, 1989.

Pandey, R. and Dashora, N.: Space weather studies at the crest of the equatorial ionization anomaly using GPS receiver, Paper presented at XXVIIIth URSI General Assembly, New Delhi, India, 23-29 October 2005.

Rama Rao, P. V. S., Srirama Rao, M., and Satyam, M.: Diurnal and seasonal trends in TEC values observed at Waltair, Indian J. Radio Space Phys., 6, 233-235, 1977.

Rama Rao, P. V. S., Nru, D., and Srirama Rao, M.: Proc. COSPAR/URSI Symp.Warsaw, Poland, edited by: Wernik, A. W., p. 51, 1980.

Rama Rao, P. V. S., Das Gupta, A., Klobuchar, J. A., and Rastogi, R. G.: Proc. Int. Beacon Satellite Symposium Physical Lab., New Delhi, India, p. 393, 1983.

Rama Rao, P. V. S., Niranjan, K., Ramana Rao, B. V., Rao, B. V. P. 
S., and Prasad, D. S. V. V. D.: Proc. URSI/IPS Conference on the Ionosphere and Radiowave Propagation Sydney, Australia, 1985.

Rama Rao, P. V. S., Gopi Krishna, S., Niranjan, K., and Prasad, D. S. V. V. D.: Temporal and spatial variations in TEC using simultaneous measurements from the Indian GPS network of receivers during the low solar activity period of 2004-2005, Ann. Geophys., 24, 3279-3292, 2006, http://www.ann-geophys.net/24/3279/2006/.

Rama Rao, P. V. S., Niranjan, K., Prasad, D. S. V. V. D., Gopi Krishna, S., and Uma, G.: On the validity of the ionospheric pierce point (IPP) altitude of $350 \mathrm{~km}$ in the Indian equatorial and lowlatitude sector, Ann. Geophys., 24, 2159-2168, 2006, http://www.ann-geophys.net/24/2159/2006/.

Rastogi, R. G. and Sharma, R. P.: Ionospheric electron content at Ahmedabad (near the crest of equatorial anomaly) by using beacon satellite transmission during half a solar cycle, Planet, Space Sci., 19, 1505-1517, 1971.

Rastogi, R. G., Sharma, R. P., and Shodan, V.: Total electron content of the equatorial ionosphere, Planet Space Sci., 21, 713-720, 1973.

Rastogi, R. G., Iyer K. N., and Bhattacharya, J. C.: Total Electron content of the ionosphere over the magnetic equator, Current Science, 44, 531-533, 1975.

Rastogi, R. G. and Klobuchar, J. A., Ionospheric electron content. within the equatorial F. 2. layer anomaly belts, J. Geophys. Res., 95, 19045-19052 1990.

Sahai, Y., Fagundes, P. R., Becker-Guedes, F., Bolzan, M. J. A., Abalde, J. R., Pillat, V. G., de Jesus, R., Lima, W. L. C., Crowley, G., Shiokawa, K., MacDougall, J. W., Lan, H. T., Igarashi, K., and Bittencourt, J. A.: Effects of the major geomagnetic storms of October 2003 on the equatorial and low-latitude F region in two longitudinal sectors, J. Geophys. Res., 110, A12S91, doi:10.1029/2004JA010999, 2005.
Sastri, J. H., Niranjan, K., and Subbarao, K. S. V.: Response of the equatorial ionosphere in the Indian (midnight) sector to the severe magnetic storm of July 15, 2000, Geophys. Res. Lett., 29(13), 1651, doi:10.1029/2002GL015133, 2002.

Sethia G., Rastogi, R. G., Deshpande, M. R., and Chandra, H.: Equatorial electrojet control of the low latitude ionosphere, J. Geomag. Geoelectr., 32, 207-216, 1980.

Spiro, R. W., Wolf, R. A., and Fejer, B. G.: Penetration of high latitude-electric-field effects to low latidudes during SUNDIAL 1984, Ann. Geophys., 6, 39-50, 1988, http://www.ann-geophys.net/6/39/1988/.

Tsurutani, B. T., Verkhoglyadova, O. P., Mannucci, A. J., et al.: Prompt Penetration Electric Field (PPEF) and their ionospheric effects during great geomagnetic storm of 30-31 October, 2003, J. Geophys. Res., 113, A05311, doi:10.1029/2007JA012879, 2008.

Van Velthoven, P. J.: Medium-scale irregularities in the ionospheric electron content, Ph.D. Thesis, Technische Universiteit Eindhoven, 1990.

Warnant, R.: The increase of ionospheric activity as measured by GPS, Earth Planets Space, 52, 1055-1060, 2000.

Wu, Chin-Chun, Liou, K., Shan, Shao-Ju, and Tseng, C. L.: Variation of Ionospheric Total Electron Content in Taiwan Region of the Equatorial Anomaly from 1994-2003, Adv. Space Res., 41, 611-616, 2008. 